\title{
Synthesis of Poly(phenylene sulfide) Containing Pendant Norbornadiene Moieties and Their Valence Isomerization
}

\author{
Takashi IIzawa, ${ }^{\dagger}$ Tomoko Kurisu, Kinue NaKaJIMa, \\ and Tadatomi NishiKUBO*, $\dagger$ \\ Department of Chemical Engineering, Faculty of Engineering, \\ Hiroshima University, Kagamiyama, Higashi-Hiroshima 739-8527, Japan \\ * Department of Applied Chemistry, Faculty of Engineering, \\ Kanagawa University, Rokkakubashi, Kanagawa-ku, Yokohama 221-8686, Japan
}

(Received November 19, 1997)

\begin{abstract}
KEY WORDS Poly(phenylene sulfide) / Norbornadiene / Quadricyclane / Chemical Modification / Photochemical Valence Isomerization / Thermal Reversion Isomerization /
\end{abstract}

We studied the synthesis of polymers containing norbornadiene (NBD) moieties and the photochemical valence isomerization of pendant NBD moieties in the polymer film. ${ }^{1-3}$ Previous papers ${ }^{4,5}$ report that introduction of NBD moiety into rigid polymer matrices such as poly(2,6-dimethyl-p-phenylene oxide) (PPO) and polyimide causes the storage and thermal stability of the obtained polymer of NBD or quadricyclane (QC) moieties to increase markedly. NBD polymers derived from poly ( $p$-phenylene sulfide) (PPS) with similar structure to PPO should show good stability. Some chemical modifications of PPS have been investigated. ${ }^{6}$
This article reports on novel synthesis of thermal stable NBD polymers ( $\mathrm{P}-2 \mathrm{a}, \mathrm{b})$ containing rigid PPS main chain prepared from the reaction of bromomethylated PPS (P-1) with potassium salt of carboxylic acid of NBD using phase transfer catalyst (PTC) (Scheme 1). We discuss effects of the rigid main chain on the photochemical valence isomerization and thermal reversion isomerization of the reactive pendants on the polymer chain, and ability of the polymers to undergo many cycles between both reactions, compared to those of the corresponding NBD polymers $(\mathrm{P}-3 \mathrm{a}, \mathrm{b})$ prepared from brominated PPO.
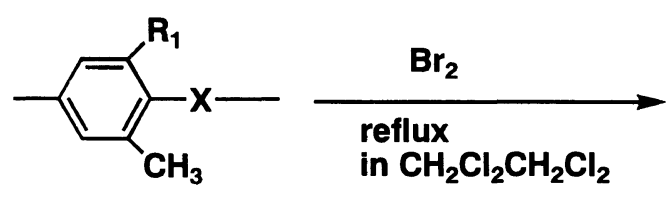

PPS ( $\left.X=S, R_{1}=H\right)$

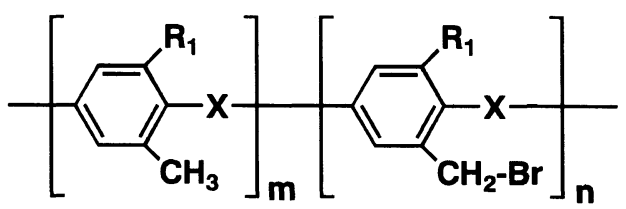

P-1 ( $\left.X=S, R_{1}=H\right)$

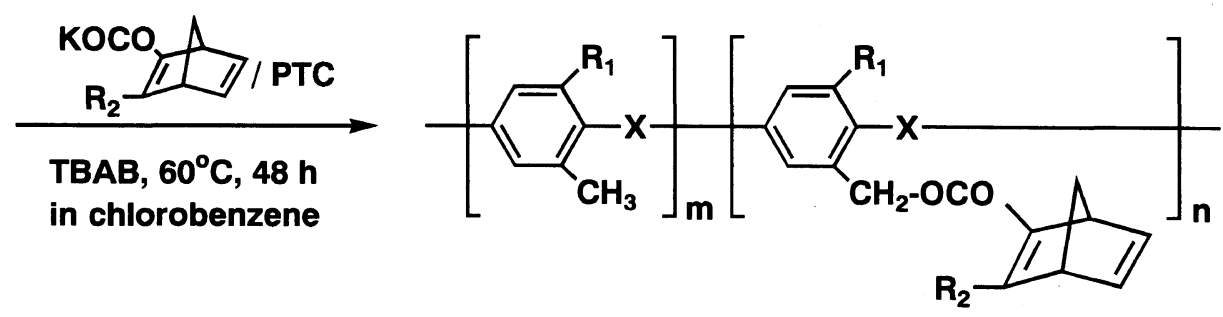

$$
\mathrm{R}_{2}=\mathrm{a}:-\mathrm{CONH} \square, \mathrm{b}:
$$

P-2a, b ( $\left.X=S, R_{1}=H\right)$

$P-3 a, b\left(X=0, R_{1}=M e\right)$
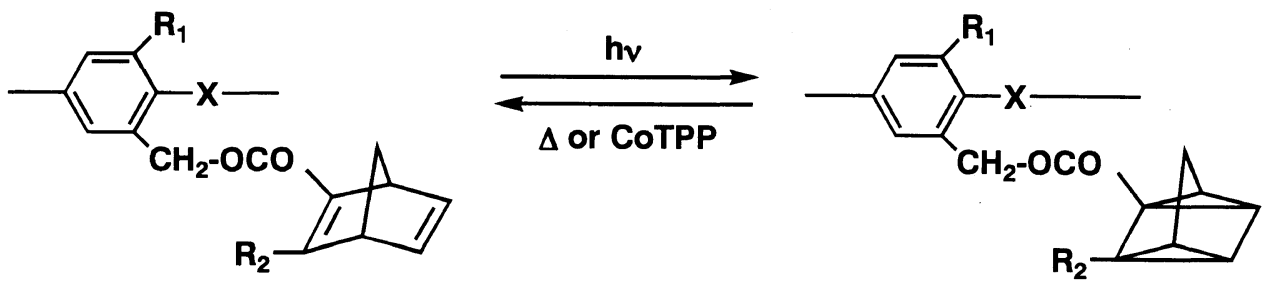

Scheme 1. Synthesis and reaction of NBD polymer.

\footnotetext{
† To whom all correspondence should be addressed.
} 


\section{EXPERIMENTAL}

\section{Materials}

The solvents were purified by distillation prior to use. 2-Methylated PPS $\left(M_{n}=2600\right)$ was donated by Idemitsu Petrochemical Co., Ltd. NBD polymers (P-3a, b, content of NBD moiety: $44.0 \mathrm{~mol} \%$ ) derived from PPO, and NBD derivatives, 3-(phenylcarbamoyl)-2,5-norbornadiene-2-carboxylic acid (NBD-a), and 3-phenyl-2,5norbornadiene-2-carboxylic acid (NBD-b) prepared previously were used. ${ }^{2-4}$ Commercial grades of bromine, dioctyl adipate (DOA), and tetrabutylammonium bromide (TBAB) were used without further purification.

\section{Typical Procedure for Synthesis of $P-1$}

To a solution of PPS containing methyl groups (12.3 g, $100 \mathrm{mmol}$ ) in $500 \mathrm{~mL} \mathrm{1,1,2,2-tetrachloroethane} \mathrm{was}$ added dropwise a solution of bromine $(2.6 \mathrm{~mL}, 50 \mathrm{mmol})$ in $100 \mathrm{~mL} \mathrm{1,1,2,2-tetrachloroethane.} \mathrm{The} \mathrm{reaction} \mathrm{mix-}$ ture was refluxed for $1.5 \mathrm{~h}$. The mixture was poured into $1 \mathrm{~L}$ methanol. The polymer was purified by reprecipitating from tetrahydrafuran (THF) solution with methanol, and dried at $60^{\circ} \mathrm{C}$ in vacuo. The yield of $\mathrm{P}-1 \mathrm{~b}$ was $5.4 \mathrm{~g}$. The degree of bromination $(n)$ was $39.3 \mathrm{~mol} \%(\mathrm{Br}$ content: $0.324 \mathrm{~g} / \mathrm{g})$. Reduced viscosity was $0.18 \mathrm{dL} \mathrm{g}^{-1}$ $\left(0.5 \mathrm{~g} \mathrm{dL}^{-1}\right.$ in chloroform at $\left.30^{\circ} \mathrm{C}\right)$. IR (film): $1190 \mathrm{~cm}^{-1}$ $(\mathrm{C}-\mathrm{O}-\mathrm{C}) .{ }^{1} \mathrm{H}$ NMR $\left(\mathrm{CDCl}_{3}\right): \delta=2.28\left(-\mathrm{CH}_{3}\right), 4.56$ $\left(-\mathrm{CH}_{2}-\mathrm{Br}\right)$, and $6.8-7.5 \mathrm{ppm}$ (aromatic protons).

Typical Procedure for Substitution Reaction of $P-1$ with Potassium Salt of NBD Derivatives Using PTC

A mixture of P-1 (degree of bromination: $39.3 \mathrm{~mol} \%$, $0.587 \mathrm{~g}, 1.50 \mathrm{mmol})$ and potassium salt of NBD-a $(0.483$ $\mathrm{g}, 1.65 \mathrm{mmol})$ was stirred using TBAB $(48 \mathrm{mg}, 0.15 \mathrm{mmol})$ as PTC in $20 \mathrm{~mL}$ chlorobenzene at $80^{\circ} \mathrm{C}$ for $24 \mathrm{~h}$. The mixture was poured into $300 \mathrm{~mL}$ methanol and reprecipitated from THF with methanol. The polymer was dried in vacuo at $60^{\circ} \mathrm{C}$ for 2 days to give $0.515 \mathrm{~g}$ of polymer. The degree of substitution of the polymer was $99.8 \mathrm{~mol} \%$, calculated from elemental analysis of bromine. The reduced viscosity was $0.44 \mathrm{dL} \mathrm{g}^{-1}$ (measured at $0.5 \mathrm{~g}$ $\mathrm{dL}^{-1}$ in chloroform at $30^{\circ} \mathrm{C}$ ). IR (film): 1690 and 1660 $(\mathrm{C}=\mathrm{O}), 1600(\mathrm{C}=\mathrm{C}), 1190 \mathrm{~cm}^{-1}(\mathrm{C}-\mathrm{O}-\mathrm{C}) .{ }^{1} \mathrm{H}$ NMR $\left(\mathrm{CDCl}_{3}\right): \delta=2.00$ and $2.08\left(-\mathrm{CH}_{2}-\right.$ of $\left.\mathrm{NBD}\right), 2.28$ $\left(-\mathrm{CH}_{3}\right), 3.92$ and $4.36(-\mathrm{CH}-), 5.37\left(-\mathrm{CH}_{2}-\mathrm{OCO}\right)$, $6.6-7.8 \mathrm{ppm}(\mathrm{CH}=\mathrm{CH}$ and aromatic protons $)$.

Typical Measurement of Photochemical Valence Isomerization of Pendant NBD Moiety in the Polymer

A solution of the polymer $(0.1 \mathrm{~g})$, DOA $(0.01 \mathrm{~g})$, and CoTPP in THF $(3 \mathrm{~mL})$ was cast on the inside wall of a quartz cell and dried. The polymer film on the cell was irradiated by a $500 \mathrm{~W}$ xenon lamp (Ushio Electric Co., UXL-500D) with a Pyrex filter at a distance of $30 \mathrm{~cm}$ in air. The rate of disappearance of maximum absorption was measured by a UV spectrophotometer.

\section{Measurement of Reversion from Pendant QC Group in the Polymer to the NBD Moiety}

The polymer film on the cell was sufficiently irradiated as described above. The rate of appearance of the maximum absorption of the resulting NBD moiety was measured at room temperature by UV spectrophoto-
Table I. Synthesis of NBD polymer from bromomethylated PPS ${ }^{\mathrm{a}}$

\begin{tabular}{|c|c|c|c|c|c|}
\hline \multirow{2}{*}{$\begin{array}{c}\text { NBD } \\
\text { polymer }\end{array}$} & \multirow{2}{*}{$m$} & \multirow{2}{*}{$n^{\mathrm{b}}$} & \multirow{2}{*}{$\frac{\text { Conv. }}{\%}$} & \multirow{2}{*}{$\frac{\text { Yield }}{\mathrm{g}}$} & \multirow{2}{*}{$\frac{\eta_{\mathrm{sp}} / C^{\mathrm{c}}}{\mathrm{dLg}^{-1}}$} \\
\hline & & & & & \\
\hline P-2a & 0.607 & 0.393 & 99.8 & 0.515 & 0.44 \\
\hline P-2b & 0.607 & 0.393 & 92.9 & 0.610 & 0.58 \\
\hline
\end{tabular}

${ }^{\text {a }}$ Reactions of bromomethylated PPS $(1.5 \mathrm{mmol}$ of bromomethyl groups) with potassium salt of NBD derivatives $(1.65 \mathrm{mmol})$ were carried out using TBAB $(0.15 \mathrm{mmol})$ in $20 \mathrm{~mL}$ chlorobenzene at $60^{\circ} \mathrm{C}$ for 2 days. ${ }^{\mathrm{b}} n$ : Degree of bromination, $m=1-n .{ }^{\mathrm{c}}$ Measured at 0.5 $\mathrm{g} \mathrm{dL}^{-1}$ in chloroform at $30^{\circ} \mathrm{C}$.

metry.

\section{RESULTS AND DISCUSSION}

NBD polymers were prepared by bromination of the methyl groups of PPS and substitution reaction of the resulting bromomethyl groups with potassium carboxylate derivatives of NBD using PTC according to the synthesis of $\mathrm{P}-3 \mathrm{a}, \mathrm{b}$ reported previously. ${ }^{4}$ The polymers containing pendant NBD moieties were obtained by reaction of $\mathrm{P}-1$ with 1.1 equivalents of potassium carboxylate derivatives of NBD using TBAB in chlorobenzene at $60^{\circ} \mathrm{C}$ for $48 \mathrm{~h}$. Reactions of $\mathrm{P}-1$ with potassium salts of NBD-a and NBD-b proceeded quantitatively to give $\mathrm{P}-2 \mathrm{a}, \mathrm{b}$, respectively, under these conditions (Table I). The IR spectrum of original P-2a film showed strong absorption at 1690 and $1660(\mathrm{C}=\mathrm{O}$ stretching), 1600 ( $\mathrm{C}=\mathrm{C}$ stretching), and $1190 \mathrm{~cm}^{-1}$ (C-O-C stretching). The ${ }^{1} \mathrm{H}$ NMR spectra of this polymer showed signals of main chain and methylene protons of the NBD moiety at $\delta=2.00$ and 2.08, methine protons at 3.92 and 4.36 , $-\mathrm{CH}_{2}-\mathrm{OCO}$ protons at 5.37, and $\mathrm{CH}=\mathrm{CH}$ and aromatic protons at $6.6-7.8 \mathrm{ppm}$. Esterification was calculated from elementary analysis of bromine, and also from the intensity of proton signals of $-\mathrm{CH}_{2}-\mathrm{OCO}$ protons at 5.37 and unreacted $-\mathrm{CH}_{2}-\mathrm{Br}$ protons at $4.56 \mathrm{ppm}$.

The photochemical reaction of polymer films was carried out by irradiation with a $500 \mathrm{~W}$ xenon lamp through a Pyrex glass filter. The typical UV spectrum change of $\mathrm{P}-2 \mathrm{a}$ and $\mathrm{P}-3 \mathrm{a}$ in the film state by irradiation is shown in Figure 1. When the P-2a film was irradiated, maximum absorption near $324 \mathrm{~nm}$ decreased and the absorption at about $252 \mathrm{~nm}$ due to the QC moiety increased. An isosbestic point was observed in the UV spectral changes of the polymers $(\mathrm{P}-2 \mathrm{a}-\mathrm{c})$ by the irradiation over $310 \mathrm{~nm}$. The spectral changes agreed with those of $\mathrm{P}-3 \mathrm{a} .{ }^{3}$ The photochemical valence isomerization of NBD in P-2a to QC moieties would thus appear to proceed selectively (eq 2). P-2a show lower photochemical reactivity than $\mathrm{P}-3 \mathrm{a}$, since the UV spectrum of $\mathrm{P}-2 \mathrm{a}$ had a strong maximum absorption near $280 \mathrm{~nm}$ due to the main chain.

QC compound is unstable, and the reversion from QC to NBD occurs gradually when stored for long time at room temperature. Previous papers ${ }^{2-4}$ report that QC moieties in polymer film became more stable than the corresponding low molecular weight $\mathrm{QC}$, and the addition of 5,10,15,20-tetraphenyl-21H,23H-porphine) cobalt(II) (CoTPP) causes the reaction to accelerate in 

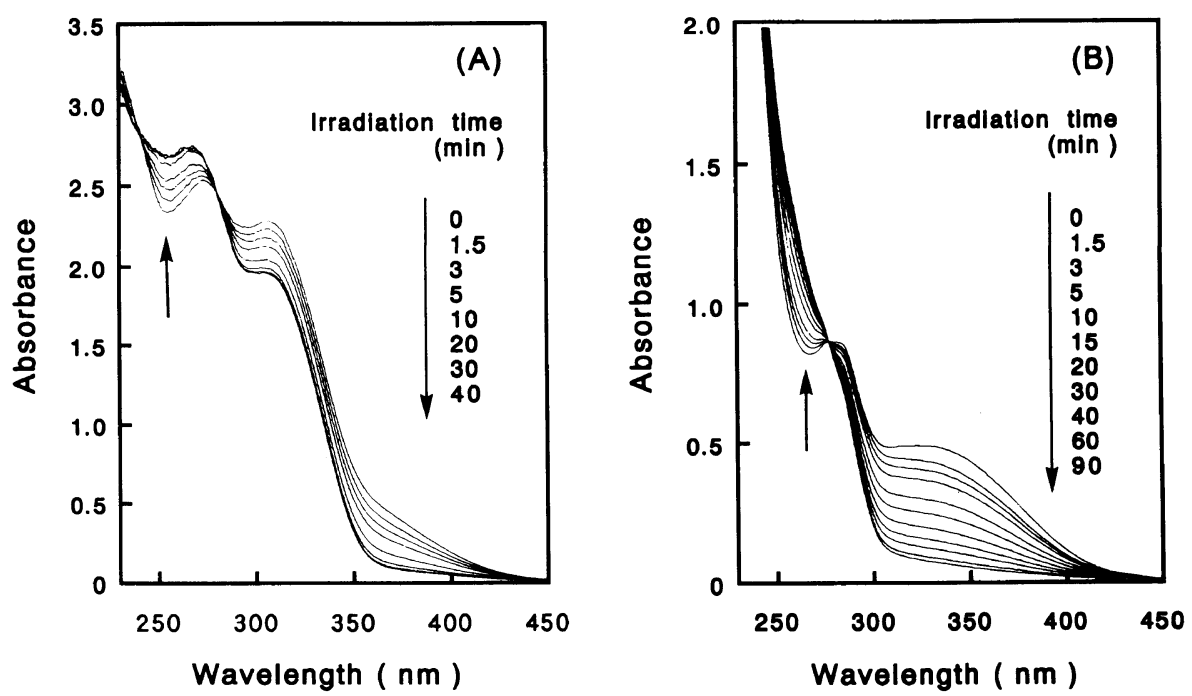

Figure 1. Change of UV spectrum: (A) Photochemical valence isomerization of P-2a film and (B) P-3a of irradiated with a 500 W xenon lamp through a Pyrex glass filter.

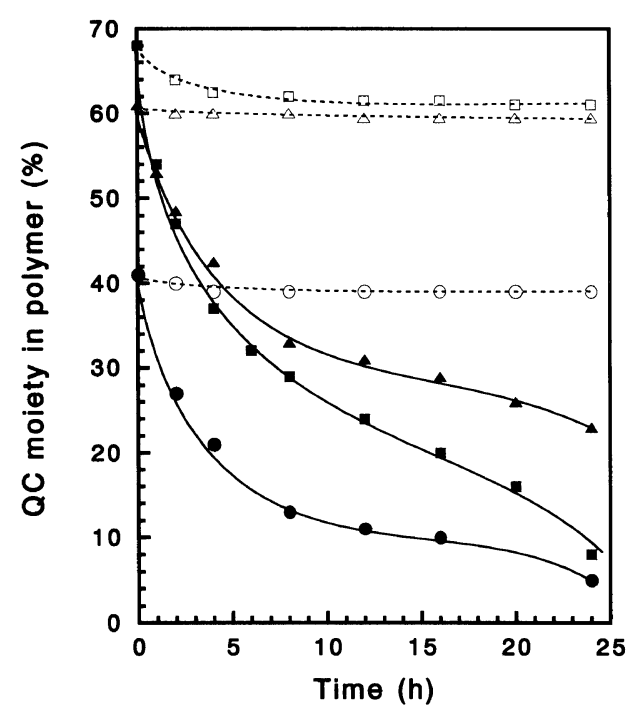

Figure 2. Catalytic reversion isomerization of irradiated polymer film with $10 \mathrm{~mol} \%$ of CoTPP. (O), P-2a; ( ), P- $2 \mathrm{a}+5 \mathrm{wt} \%$ of DOA; $(\triangle)$, $\mathrm{P}-3 \mathrm{a} ;(\boldsymbol{\Delta}), \mathrm{P}-3 \mathrm{a}+5 \mathrm{wt} \%$ of DOA; $(\square), \mathrm{P}-3 \mathrm{~b} ;(\square), \mathrm{P}-3 \mathrm{~b}+5 \mathrm{wt} \%$ of DOA.

the film state as well as solution. However, the catalytic reversion reaction hardly took place in rigid polymer matrices such as PPO and PPS at room temperature (Figure 2). When $5 \mathrm{wt} \%$ of DOA was added to the polymer as a plasticizer, the reversion proceeded smoothly although the photochemical valence isomerization was not altered. This suggests that the plasticizer promotes the isomerization from QC to NBD in the polymer film. However, the addition of excessive DOA made the film opaque and interfered with the photochemical valence isomerization. When the plasticizer and CoTPP were added to the polymer films, photochemical valence isomerization of the NBD moiety to QC moiety by irradiation and catalytic reversion of the resulting QC moiety to the original NBD moiety at room temperature for $24 \mathrm{~h}$ were repeated (Figure 3), causing reversion of QC group to decrease gradually and photochemical reaction to increase. Significant decay of the amplitude of QC groups and decomposition of NBD and QC groups
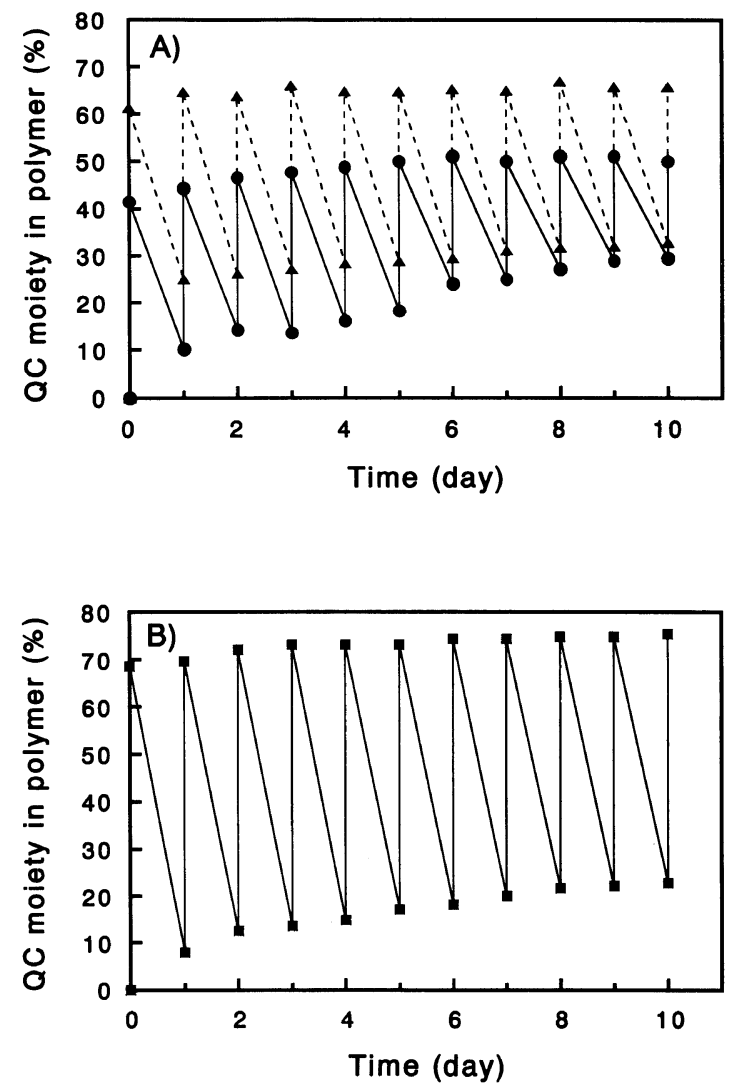

Figure 3. Time of photochemical valence isomerization of a polymer with $10 \mathrm{~mol} \%$ of CoTPP and $5 \mathrm{wt} \%$ of DOA upon irradiation and catalytic reversion isomerization at room temperature for $24 \mathrm{~h}$. A) (O), P-2a $;^{\mathrm{a}}(\boldsymbol{\Delta}), \mathrm{P}-3 \mathrm{a} ;{ }^{\mathrm{a}}$ B) (ם), P-3b. ${ }^{\mathrm{b}}$

${ }^{\mathrm{a}}$ Irradiation carried out for $30 \mathrm{~min}$. ${ }^{\mathrm{b}}$ Irradiation carried out for $5 \mathrm{~min}$.

were not observed by the repetition. The stability of P-2a is almost the same as that of P-3a and P-3b.

The reversion from $\mathrm{QC}$ to $\mathrm{NBD}$ was accelerated and proceeded without any catalyst when the QC compound was heated. The QC polymer prepared from poly( $p$-chloromethylstyrene) decomposed under these conditions, and thermal reversion was not observed. The 


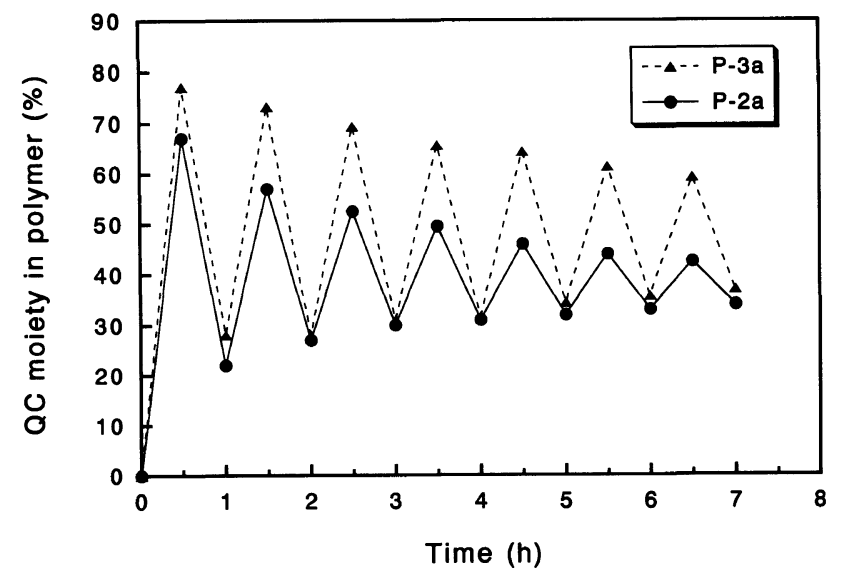

Figure 4. Time of photochemical valence isomerization of a polymer on irradiation for $30 \mathrm{~min}$ and thermal reversion isomerization at $160^{\circ} \mathrm{C}$

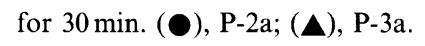

IR and UV spectra of the heated polymer were similar to those of the original NBD polymer, P-2a. The thermal reversion of QC moieties in the PPS matrix occurred. The photochemical valence isomerization of NBD moiety of P-2a to QC moiety by irradiation for $30 \mathrm{~min}$ and thermal reversion of the resulting QC moiety to the original NBD moiety at $160^{\circ} \mathrm{C}$ for 30 min repeated more than 7 times (Figure 4). Although P-2a and P-3a gradually degraded, P-2a showed less thermal stability than P-3a.

NBD or QC moieties in PPS thus have high thermal stability. However, the photochemical valence isomerization and the thermal stability are slightly lower than those of the corresponding PPO polymer.

\section{REFERENCES}

1. T. Iizawa, Kobunshi, 45, 316 (1996).

2. T. Nishikubo, C. Hijikata, and T. Iizawa, J. Polym. Sci., Part A, Polym. Chem., 29, 671 (1991).

3. T. Iizawa, C. Hijikata, and T. Nishikubo, Macromolecules, 25, 21 (1992).

4. T. Iizawa, T. Sueyoshi, C. Hijikata, and T. Nishikubo, J. Polym. Sci., Part A, Polym. Chem., 32, 3091 (1994).

5. T. Iizawa, H. Ono, and F. Matsuda, Reactive Polymer, 30, 17 (1996).

6. For example a) A. A. Dembek, P. J. Fagan, and M. Marsi, Macromolecules, 26, 2992 (1993); b) Y. Ding and A. S. Hay, ibid., 30, 2527 (1997); c) K. Miyatake, E. Shouji, K. Yamamoto, and E. Tsuchida, ibid., 30, 2941 (1997). 